\title{
Designing a Rubric to Assess the Modelling Phase of Student Design Projects in Upper Year Engineering Courses
}

\author{
Thomas F.C. Woodhall \\ Masters Candidate in Civil Engineering \\ Queen's University at Kingston, Ontario \\ woodhallt@appsci.queensu.ca
}

\author{
David S. Strong \\ Professor \& NSERC Chair in Design \\ Engineering \\ Queen's University at Kingston, Ontario \\ strongd@appsci.queensu.ca
}

\begin{abstract}
In order to bridge the gap between a student's understanding and an instructor's perception of subject mastery, it is important to assess upper year capstone design projects in a way which targets the important aspects within each stage in the design process while providing feedback that is instructive and helpful. Using the design process itself a rubric was created that assesses a student's mastery of the modelling phase of the design project (as defined by Dominik). The rubric assesses students in two areas: key concepts and key steps. These areas fully encompass the goals of the modeling phase, not only in terms of the project's completion, but also relate to the learning goals that instructors should have for the student, as well as providing feedback that can help develop a student's mastery of the topic area.
\end{abstract}

\section{Introduction}

Many Engineering institutions are making active steps to increase the amount of design education that is being taught in their programs. Coupled with an effort to increase the amount of design throughout the engineering curriculum should be an improved and relevant method for assessing the learning exhibited by these students. Within the design process exist independent phases, each with different learning objectives for students. Assessment of these objectives and of the phases themselves is not only easier for the instructor then assessing the entire design process, but also provides students feedback as they progress from problem definition to final design. Using a progressive depiction of the design process such as that described by Dominick [4], a rubric assessment using the ICE approach [10] can be developed to highlight to both students and instructors the learning objectives, and to assess completely these objectives, for the modelling phase of the design process.

\section{Assessment of Design Phases within the Design Process}

While it is important, and in fact necessary according to most accreditation institutions, to teach undergraduate engineering students design, it is also very necessary to ensure that students are being assessed appropriately. The design process can be broken down into a series of steps, which aid not only the designer or student in understanding where they are in the process of creating a finished design, but also help the instructor in assessing the learning that the student is engaging in. Assessing the design process appropriately is essential for the student to engage in deep learning, and in fact the assessment process itself steers such learning [1]. Due to this link between assessment and learning, it is necessary to ensure that each of the learning goals for teaching design is assessed appropriately. To create an environment within which the design process is assessed with the goal of deep learning it is necessary to have a clear view of the learning outcomes that the instructor is striving to instil in the students [2]. This serves as strong justification to create an overarching assessment scheme that involves breaking down each of the phases of the design process into their separate elements and within each phase into separate learning outcomes. As part of this larger assessment scheme, this paper strives to describe a comprehensive assessment tool for measuring student learning during the modelling phase of the design process. In addition to this tool assisting instructors in measuring their ability to transfer the learning objectives to the students, it also is intended to motivate students. As Oehlers points out, there is a body of work that shows how students are directly motivated by what they are being assessed on [1]. By pointing out to students the benefits of advancing through the modelling phase, they are likely to engage more actively in the process. 
Coupling with this is an emphasis that the final product of the modelling phase is not the sole criterion on which students will be evaluated. One of the most important elements of the modelling phase is the learning that is done during fabrication [3]. It is important that this is made clear to both the assessor and the student. While the output of the phase, either a comprehensive and responsive model or a physical prototype, is important and can advance the project in important directions, it is essential that the mental processes involved are emphasised as they will last the student well into their professional career [1].

\section{Modelling and Prototyping}

Within the design process the role of the modelling phase can have a significant impact on the quality of the final design, as well as enhance the learning that students gain from engaging in the design process. It is important to understand the differences between modelling and prototyping and the benefits they can offer over sketches, computer graphics and paper mock-ups. Before discussing the inherent benefits of having students engage in the modelling/prototyping phase of the design process, it is important to create a distinction between the two.

Modelling, building on Dominick et. al.'s definition, is a way of virtually representing your design not only in terms of physical characteristics (size, weight, etc) but also in terms of behaviour and use [4]. A systematically designed and accurate model allows for virtual testing as well as visualization of the design.

Prototyping is often defined as a working physical model of the key components of the design. While full sized models are ideal, scale model prototypes are often just as effective in many situations. Although often more expensive and complex, physical prototypes offer designers a hands on experience that allows for design issues to surface in ways that are not possible except by constructing and refining a physical prototype [3]. However, there may be drawbacks to physical prototypes, often entailing limited resources (money, time, materials) or the ability to simulate the operating environment. In such situations, a virtual model may be more appropriate.

\section{The Modelling Phase: Benefits to the student and the design}

By highlighting the modelling phase as an important part of the design process, it emphasises to the student the benefits of going beyond paper design in order to optimize the final design, and to enhance learning. One of the most important objectives of the modelling phase is a validation of the design to that point. Students lack the experience that helps professional designers and engineers move efficiently through the design process. As a result, students can face one of two scenarios with an inappropriate design. The lack of experience with an untested design can leave students feeling lost or confused on the direction of their project, and can slow them from making advances to the next stage of design refinement. Alternately, due to students' inexperience they may feel locked into a certain direction, believing it to be the only path to success of the project. Validation through modelling and prototyping allows students to challenge and prove or disprove their theories to this point in the design. By asking and answering their own questions through modelling and prototyping, students advance to higher order questions that would not have been possible otherwise [3]. This exploration process through validation is one of the learning outcomes that is beneficial during the modeling process and should become part of the assessment criterion.

By engaging in the modelling phase and using it appropriately, students can quickly advance their project, helping to achieve a higher quality final solution in addition to developing their own skill set. Through modelling students can develop a deeper understanding of their design and its constraints [4]. Although critical thinking and theorizing can help students to develop potential problems or advantages in their designs, it is only through testing that these ideas can be fully realized [3]. Modelling also allows students to see how different components of the design interact with each other. It has also been proven to help students convey their ideas to others [4]. This can be especially beneficial to both the students and the instructors because it allows students with limited communication skills with respect to design concepts, to relay their designs or concerns to instructors who may be supervising a number of design groups (and therefore might have difficulty becoming fully engrossed with each group). Modelling can help students not only improve their design communication skills, but can help students understand the benefits and limitations of their designs.

Further, students themselves develop important skills that will benefit them in their burgeoning professional careers. Custer et. al. describe modelling as a "key mental process" which is utilized by all manner of technological professionals [5]. Employer surveys consistently suggest that graduate engineers are in need of the skills developed in the design process, including the "practical skills" developed in the modelling phase, yet many undergraduate 
engineering programs fall short in meeting this need [6]. The ability to develop and decide on the materials, process and techniques for modelling, as well as the ability to interpret results, iterate and improve the design, are all important and desirable skills. Although students are sure to benefit from the technical skills associated with using a particular model or gain proficiency in using a specific tool to build a prototype, these skills will obsolesce. The true benefit to be had is the development of the mental processes that students will carry through their professional careers [2]. Beyond the direct skills learned through modelling, students engaged in such an intensive and hands on process will learn valuable team skills that will also benefit their education and careers [7].

As discussed by Hill, the technological skills developed by students, while important, are not the ultimate goal of teaching modelling and prototyping to students. The mental processes of developing, testing, and iterating a model should be the primary instructional goals. From this stems the need to assess the learning that students acquire as they progress through the modelling phase, rather than simply assessing the model itself.

\section{Quality Assessment For Learning}

Proper assessment of student design projects is important to ensure that learning is effective and that the work has legitimacy in the eyes of students. As discussed previously, students respond positively to thorough and accurate assessment. Design projects are inherently difficult to assess due to their openended nature. Conventional assessment techniques, including tests and assignments, might not be appropriate [8]. Most important to the assessment of the modelling phase is that it is clear to instructor and student that the output is not the sole metric on which learning is being judged.

In an effort to accurately measure student learning, it is proposed that the design process should be assessed using an appropriate rubric. By using effective rubric assessment, both instructors and students can more easily determine the level of learning that has been achieved. Rubrics also allow for feedback to be given to students on their activities and learning that is descriptive and corrective [9].

The ICE approach of assessment [10] is a technique for measuring the degree to which students are moving through different stages of learning, from novice through expert. The approach uses three different stages of learning. The first or Ideas stage represents the basic building blocks of learning. Within this stage students should be assessed on their understanding of the basic steps involved in a process, the necessary vocabulary, and an introductory skill set. Secondly students progress to the Connections stage. Connections occur when students are able to demonstrate they understand relationships between different elements learned in the Ideas phase. Lastly students progress to mastery of the topic in the Extensions stage. At this stage learners internalize the material and are able to develop new learning on their own [10]. The ICE approach allows for instructors to fully articulate to students where their understanding of the material is. It also allows for instructors to provide feedback on what students must to do advance to the next stage of understanding.

The scoring elements of the rubric can be broken down into two principle categories. The Key Concepts portion is concepts that are important to understand about the modeling phase. These represent the core of why this phase is important to the design process and how it relates to the final design of the object. The Key Steps portion of the rubric relates to more tangible steps undertaken when progressing through the modeling phase. These can take on a very practical side in terms of using tools or interpreting results but also represent underlying theories that are important for the student to master.

While assessing the modelling phase of the design process it is important to keep in mind the goals of using a formative assessment strategy. Ultimately, the goal of assessing a portion of the design process is to assist student motivation and learning. This is a primary objective of formative assessment, which uses a circular process of evaluating, providing feedback, and correction instruction [9]. Much like the modelling process takes a formative role within the design process itself, involving an evaluation of the current design, feedback from tests or trials, and corrections and improvements to the design, the assessment of such activities should promote deeper learning of the process to the students as well as helping them reach the end goal of a successful design.

\section{Key Concepts}

By adopting Dominick et al.'s outline for the design phase, it is logical to employ a breakdown of the modeling phase using the same literature in order to help form the evaluation criteria of the rubric. There are four general reasons why designers create models and prototypes, and these will form an important part of the rubric assessment.

The first reason for the modeling phase of the design cycle is that it gives the designer a better and more complete understanding of potential problems. 
As Dominick points out "they help engineers integrate information gathered about the design project with what they might have envisioned in their minds" [4]. For students to show an understanding of the importance of models they should be able to articulate how the model has developed their understanding of their design project and any potential problems or limitations.

A second reason for using the modeling phase during the design process is to save the designer and the client (sometimes the same entity) time and money. Whether the model is a virtual one or a physical prototype information gathered about the object can prevent costly initial outlays of time, money and resources [4]. In order for the student to show a mastery of this part of modeling it is important for them to recognize what benefits have been gained by using the model as well as demonstrating they understand the model's shortcomings.

Modeling also allows for refinement and improvement of initial design ideas. By creating a model that is easily modifiable, the designer can change parameters without incurring significant costs (time, money or resource costs) which allows for greater iteration in the design process. Adjusting and learning from the model allows the designer to fully appreciate what is going on in the design [4]. Students should be able to show a continual experimentation and eventual improvement of the design using the model.

During the design process it is quite easy for two designers to think in very different terms but have trouble articulating their concepts. Models are helpful at conveying information and ideas, not even just between designers but between a designer and a client, a manufacturer, or other relevant groups [4]. For students to show complete understanding of this step they must demonstrate how their models help to convey information and to clarify their ideas for other parties.

\section{Key Steps}

As a designer engages in the design process there are steps to undertake within the modeling phase itself, and these are important for students to progress through to ensure deep learning of the material.

Selecting an appropriate modeling process is an important step when designing. The designer must be aware of many different types of models and must be able to choose which one best suits the current design's needs. Knowledge of predictive vs. descriptive models by the student is key to demonstrating the proper use of model selection [4].
While choosing the correct model is difficult (and can be difficult for the instructor to assess as a judgment decision), the student should be able to justify and explain their choice.

Another important step in the modeling process stems from earlier portions of the design phase related to problem definition. When using a model, students must clearly demonstrate what they hope to achieve with it. They need to be able to objectively evaluate the model outputs and results to determine if it is meeting the criteria set out earlier in the design process [4].

Testing is an important step in the design process because it fully investigates how the different parts of a model or design work together as a unit. It helps demonstrate strengths and weakness that might have been unexpected but also might reinforce or breakdown preconceived notions that arose during the design process [4]. Students should be able to demonstrate a proficiency in testing their model as well as being able to represent and interpret their results objectively.

At this point in the design process, it is important for students to re-evaluate and revisit the design. A critical analysis of the key parts of the design and how they might hinder the final product is important to the success of the project. Students should be reflecting on what the original requirements for the design were and how they relate to the current design [4]. A deep understanding can be demonstrated by explaining the shortcomings of the model that might affect the final design.

\section{Assessment Rubric}

The ICE assessment rubric for Key Ideas can be found as Table 1 and Key Steps as Table 2.

\section{Conclusion}

By breaking down the design process into independent phases, and then articulating the learning goals and objectives within each phase, instructors are able to assess clearly and easily the learning accomplished by their students. Similarly, with an effective rubric that clearly describes levels of development, students are able to see where they need to progress to ensure complete understanding and mastery of the subject. 


\section{Rubric Assessment Tables}

Table 1. Assessment Rubric for Key Concepts

\begin{tabular}{|c|c|c|c|}
\hline Element & Ideas & Connections & Extensions \\
\hline $\begin{array}{l}\text { Develop a } \\
\text { better } \\
\text { understanding } \\
\text { of the design } \\
\text { problem and } \\
\text { possible } \\
\text { solutions }\end{array}$ & $\begin{array}{l}\begin{array}{l}\text { Adequately explains } \\
\text { design success } \\
\text { criteria }\end{array} \\
\text { Adequately explains } \\
\text { potential design } \\
\text { pitfalls and failures }\end{array}$ & 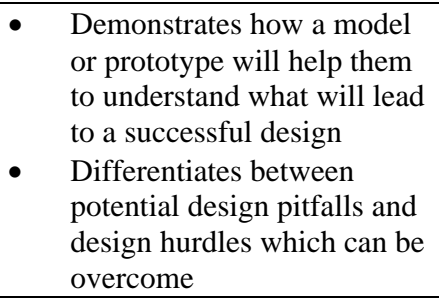 & $\begin{array}{l}\text { Uses the modeling process to modify } \\
\text { or accent initial design criteria } \\
\text { - } \quad \text { Shows how initial design modeling has } \\
\text { changed or improved the final design } \\
\text { - } \quad \text { Uses a model or prototype to enhance } \\
\text { understanding of the subject area }\end{array}$ \\
\hline $\begin{array}{l}\text { To save time } \\
\text { and money }\end{array}$ & $\begin{array}{l}\text { Understands the } \\
\text { usefulness of } \\
\text { modeling and } \\
\text { prototyping in } \\
\text { conserving resources } \\
\text { (money, time, other) }\end{array}$ & $\begin{array}{l}\text { - Shows how their design } \\
\text { project is improved by } \\
\text { modeling }\end{array}$ & $\begin{array}{l}\text { Uses conserved resources towards } \\
\text { improvement of the design } \\
\text { Clearly shows how client benefits from } \\
\text { modeling }\end{array}$ \\
\hline $\begin{array}{l}\text { Refining ideas } \\
\text { to achieve } \\
\text { optimal } \\
\text { working } \\
\text { solution }\end{array}$ & $\begin{array}{l}\text { Explains how } \\
\text { modeling will be } \\
\text { used to iterate the } \\
\text { design }\end{array}$ & 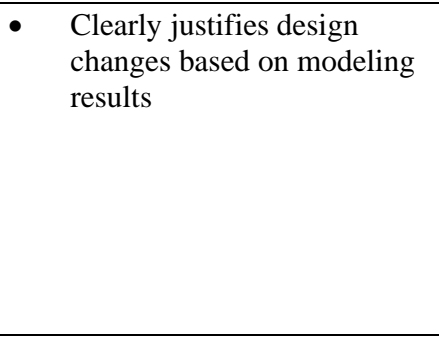 & 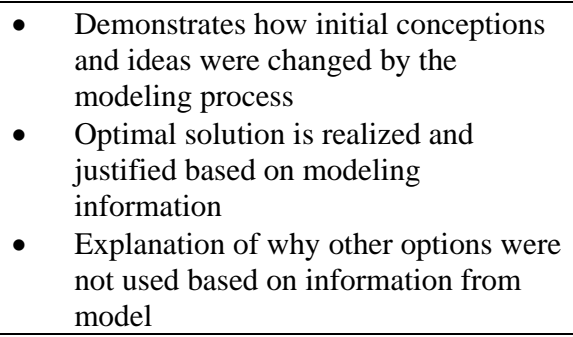 \\
\hline $\begin{array}{l}\text { Helps convey } \\
\text { ideas and } \\
\text { information }\end{array}$ & $\begin{array}{l}\text { Uses a model to } \\
\text { explain the basic } \\
\text { concepts of initial } \\
\text { design }\end{array}$ & $\begin{array}{l}\text { Uses model to show } \\
\text { strengths and weakness of } \\
\text { initial design and how final } \\
\text { design might be affected }\end{array}$ & 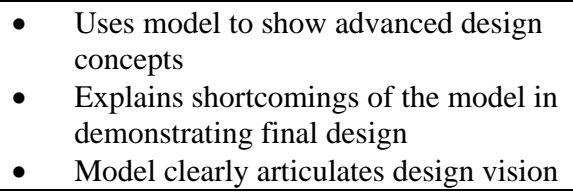 \\
\hline
\end{tabular}

Table 2. Assessment Rubric for Key Steps

\begin{tabular}{|c|c|c|c|}
\hline Element & Ideas & Connections & Extensions \\
\hline $\begin{array}{l}\text { Selecting a } \\
\text { modeling } \\
\text { process }\end{array}$ & $\begin{array}{ll} & \text { Understanding several } \\
\text { different types of } \\
\text { modeling processes }\end{array}$ & $\begin{array}{l}\text { Shows understanding of } \\
\text { specific advantages and } \\
\text { disadvantages of different } \\
\text { modeling processes } \\
\text { - Selects an modeling process } \\
\text { that enables some feedback } \\
\text { on the design }\end{array}$ & $\begin{array}{l}\text { - Selects a modeling process that } \\
\text { highlights the designs shortcomings } \\
\text { and potential problems } \\
\text { Uses the given strengths and weakness } \\
\text { of the chosen modeling process to } \\
\text { improve the design }\end{array}$ \\
\hline $\begin{array}{l}\text { Performing } \\
\text { design } \\
\text { analyses }\end{array}$ & $\begin{array}{l}\text { - Understands what } \\
\text { types of analyses are } \\
\text { typical in a modeling } \\
\text { phase }\end{array}$ & $\begin{array}{l}\text { - } \begin{array}{l}\text { Analysis performed reflects } \\
\text { original goals and criteria of } \\
\text { the problem }\end{array} \\
\text { - Appropriate analysis tools } \\
\text { are used to assess the design }\end{array}$ & $\begin{array}{l}\text { Proper analysis tools were used to } \\
\text { assess strengths and weakness of the } \\
\text { design } \\
\text { Results of analysis are interpreted to } \\
\text { the benefit of the design and the client } \\
\text { - } \begin{array}{l}\text { Design is modified and justified } \\
\text { according to analysis results }\end{array}\end{array}$ \\
\hline $\begin{array}{l}\text { Testing the } \\
\text { overall design }\end{array}$ & $\begin{array}{l}\text { - } \quad \begin{array}{l}\text { Understands and } \\
\text { articulates the benefits } \\
\text { of testing a model }\end{array}\end{array}$ & $\begin{array}{l}\text { - } \quad \text { Tests the model } \\
\text { Clearly states the results } \\
\text { and what they might mean } \\
\text { for the model }\end{array}$ & $\begin{array}{l}\text { Interprets test results with regards to } \\
\text { model performance, original design } \\
\text { criteria, and problem definition } \\
\text { Provides feedback on the design based } \\
\text { on test results }\end{array}$ \\
\hline $\begin{array}{l}\text { Revising, } \\
\text { refining, and } \\
\text { critiquing the } \\
\text { design }\end{array}$ & $\begin{array}{ll} & \text { Revisits original } \\
\text { design and makes } \\
\text { improvements }\end{array}$ & $\begin{array}{l}\text { Identifies weakness in the } \\
\text { design that can be corrected } \\
\text { Uses test results to improve } \\
\text { the model and the final } \\
\text { design }\end{array}$ & $\begin{array}{l}\text { - Critiques the design in terms of } \\
\text { original design criteria } \\
\text { - } \quad \text { Improves upon design based on test } \\
\text { results }\end{array}$ \\
\hline
\end{tabular}




\section{References}

[1] D. J. Oehlers, "Sequential assessment of engineering design projects at university level," European Journal of Engineering Education, vol. 31, no. 4, pp. 487, 2006.

[2] Hill, "The design of an instrument to assess problem solving activities in technology education," Journal of Technology Education, vol. 9, pp. 31, 1997.

[3] Yang, "A study of prototypes, design activity, and design outcome," Design Studies, vol. 26, pp. 649, 2005.

[4] Dominick, Tools and Tactics of Design. 2001
[5] Custer, "An assessment model for a design approach to technological problem solving," Journal of Technology Education, vol. 12, pp. 5, 2001.

[6] E. E. May, "Engineering Design Education: Education Meets Industry," 2006.

[7] Ivins, "Interdisciplinary project work: practice makes perfect?" IEEE Transactions on Education, vol. 40, pp. 179, 1997.

[8] I. S. GIBSON, "Assessment Criteria for Undergraduate Project Work in Engineering Design," European Journal of Engineering Education, vol. 23, no. 3, pp. 389, 1998.

[9] J. McMillan, Classroom Assessment. 2007

[10] Young, Assessment Learning the Ice Approach. 2000 